\title{
Characterization and Biodegradation Studies for Interpenetrating Polymeric Network (IPN) of Chitosan-Amino Acid Beads
}

\author{
Manjusha Rani ${ }^{1}$, Anuja Agarwal ${ }^{1}$, Yuvraj Singh Negi ${ }^{2}$ \\ ${ }^{1}$ Department of Chemistry, J. V. Jain College, Saharanpur (U.P.), India; ${ }^{2}$ Polymer Science and Technology Program, Department of \\ Paper Technology, Saharanpur Campus, Indian Institute of Technology, Roorkee, Saharanpur (U.P.), India \\ Email:dr_yuvrjas_negi@yahoo.co.in
}

Received December $4^{\text {th }}, 2010$; revised December 16 ${ }^{\text {th }}, 2010$; accepted December $20^{\text {th }}, 2010$.

\begin{abstract}
The paper describes the synthesis of $p H$ sensitive interpenetrating polymeric network (IPN) beads composed of chitosan, glycine, glutamic acid, cross linked with glutaraldehyde and their use for controlled drug release. The drug was loaded into beads by varying their composition such as, amount of crosslinker glutaraldehyde, ratio of chitosan, glycine and glutamic acid. The beads were characterized by fourier transform infrared (FTIR) spectroscopy to confirm the cross linking reaction and drug interaction with crosslinked polymer in beads, Scanning Electron Microscopy (SEM) to understand the surface morphology and Differential scanning calorimetry (DSC) to find out the thermal stability of beads. $X$-Ray Diffraction (XRD) investigation was carried out to determine the crystalline nature of drug after loading into chitosan-glycine-glutamic acid IPN beads. Results indicated amorphous dispersion of chlorpheniramine maleate (CPM) in the polymeric matrix. The swelling behavior of the beads at different time intervals was monitored in solutions of $\mathrm{pH}$ 2.0 and $\mathrm{pH}$ 7.4. The release experiments were performed in solutions of $\mathrm{pH} 2.0$ and $\mathrm{pH} 7.4$ at $37^{\circ} \mathrm{C}$ using chlorpheniramine maleate (CPM) as a model drug. The swelling behavior and release of drug were observed to be dependent on $\mathrm{pH}$, degree of cross linking and their composition. The results indicate that the cross linked IPN beads of chitosan-glycine-glutamic acid might be useful as a vehicle for controlled release of drug. The kinetics of drug release from beads was best fitted by Higuchi's model in which release rate is largely governed by rate of diffusion through the matrix.
\end{abstract}

Keywords: Cross-Linked Beads, Chitosan, Chlorpheniramine Maleate, Glycine, Glutamic Acid, Controlled Drug Release

\section{Introduction}

Recently efforts have been made to design novel drug dosage formulations so that more and more effectiveness could be altered to the conventional dosage forms. To achieve this goal controlled release technology had developed the commercial methodology by which pre decided and reproducible release of drug up to therapeutic level into a specific environment over a prolonged time period could be maintained. Such drug delivery systems function according to the changes in physiological signals with in the body and target the drug for the site of action to minimize any side effect. Nano and micro beads of polymers have been formulated using polymeric material either synthetic or natural [1-3] origin. Therapeutic molecules complexed by beads of polymers capable of forming gel, may also be released by diffusion. Hence, drug delivery system require polymeric matrix which would be non toxic, biocompatible, biodegradable.

Chitosan is such a valuable natural biocompatible polymer, nontoxic, biodegradable [4,5], mucoadhesive [6,7], easily bio absorbable [8] and also posses gel forming ability at low $\mathrm{pH}$ [9]. Moreover, it has antacid and anti ulcer activities $[10,11]$ which prevent or weaken drug irritation in the stomach. All these interesting properties of chitosan make this natural polymer an ideal element for formulating drug delivery devices [12-15] and this material has been used to form drug carrying systems for several biomedical purposes [16-20] and also for gene therapy [21-23] to suture and wound healing [24] materials, vascular grafts [25] and cartilage regeneration [26] among many other applications $[27,28]$. 
Chitosan is obtained by N-deacetylation of chitin which is naturally abundant muco polysaccharide and forms the exoskeleton of crustaceans, insects etc. It is well known to consist of 2-acetamido 2-deoxy $\beta$-D-glucose through a $\beta(1 \rightarrow 4)$ linkage [29]. Thus, chitosan is a hetero polymer having $(1 \rightarrow 4)$ 2-amino 2-deoxy $\beta$-D-glucose unit with $(1 \rightarrow 4)$ 2-acetamido-2 deoxy $\beta$-D-glucose units of original chitin in polymeric chain. The ratio of 2-amino-2-deoxy $\beta$-D-glucose unit to 2 -acetamido-2-deoxy $\beta$-D-glucopyranose is an important parameter called as degree of deacetylation which determines its solubility and solution or gel forming properties. Chitosan is highly basic polysaccharide. It is soluble in dilute acids. It posses property of forming hydrogels which are highly swollen hydrophilic polymer network, capable of absorbing large amounts of water and widely used in controlled release system [30]. Recently, $\mathrm{pH}$ sensitive hydrogels [31] have potential use in site specific delivery of drug. Some of the most appealing characteristics of chitosan are its bio adhesive properties and its ability to promote cell proliferation and consequently, tissue regeneration [27,28]. These properties of chitosan are enhanced upon decreasing the polymer's degree of acetylation [32,33] and are of outmost importance for biomedical engineering.

Beads are solid, spherical, micron or nano sized drug carrier particles constituting a matrix type of structure. Drug may be either absorbed at the spherical beads or entrapped with in it. In other words, these are just like vesicular system surround a cavity consisting drug persists in polymeric solid. These polymeric beads are advantageous over pellets including relatively higher intercellular uptake. Their charge properties influence the uptake by intestinal epithelia. The beads obtained from hydrophobic polymers have found to be higher uptake as compared to the beads prepared from more hydrophilic surfaces [34]. So nano / micro beads surface charges and increased hydrophobicity of polymeric matrix have been found to be effective for the gastrointestinal uptake in a positive sense.

Our study is an attempt to develop cross linked beads composed of chitosan and two amino acids as spacer groups cross linked with glutaraldehyde for sustained release of chlorpheniramine maleate as a model drug to investigate the swelling behavior and modeling drug release properties. No literature about such crosslinked beads constituting chitosan with two amino acids are yet found although there are some reports in the literature in which tripeptide $[35,36]$ have been used as spacer arm group to obtain drug carrier beads. The synthesis of polypeptide to be used as spacer arm in the polymer is a complicated process. Therefore, we decided to use an alternative to this approach. We planned a study to obtain drug carrier beads of chitosan with constituent amino acid of the polypeptide (to be used as a spacer arm) which may be fruitful for further studies.

The present study includes the use of two amino acids glycine and glutamic acid with cross linked chitosan polymer. We had studied earlier [37] to find out difference in its characteristics, swelling behavior and drug release with the cross linked chitosan beads and cross linked chitosan amino acids beads containing only one amino acid either glycine or glutamic acid.

\section{Materials and Methods}

Chitosan was purchased by India Sea Food, Kerala, and was used as received. Its percentage of deacetylation after drying was $89 \%$. Chlorpheniramine maleate (CPM) i.e. $\mathrm{C}_{16} \mathrm{H}_{19} \mathrm{ClN}_{2} \mathrm{C}_{4} \mathrm{H}_{4} \mathrm{O}_{4}$ was obtained as a gift sample from Sarthak Biotech Pvt. Ltd., HSIDC, Haryana, India. Glutaraldehyde, glycine and monosodium glutamate were procured from SD Fine Chemicals Ltd., Mumbai, India, Sisco Research Laboratories Pvt. Ltd., India and Reidal Chemicals, India respectively. All other chemicals used were of analytical grade. Double distilled water was used in throughout the studies.

\subsection{Preparation of Semi-Interpenetrating Polymer Network (IPN) Beads}

Different IPN beads (G1-G8) varying in composition were prepared separately. Their composition is described in "Table-1". Weighed quantity of chitosan and amino acid were dissolved in $40 \mathrm{ml}$ of $2 \%$ acetic acid by weight and stirred for three hours using magnetic stirrer at room temperature. The homogeneous mixture was extruded in the form of droplets using a syringe into $\mathrm{NaOH}$-methanol solution $(1: 20 \mathrm{w} / \mathrm{w})$ under stirring condition at $400 \mathrm{rpm}$. The beads were washed with hot and cold water respectively. The resultant beads were allowed to react with glutaraldehyde solution as given in "Table-1" at $50^{\circ} \mathrm{C}$ for about 10 minutes. Finally the cross linked IPN beads were successively washed with hot and cold water followed by air drying.

Table 1. Composition of IPN beads.

\begin{tabular}{cccccc}
\hline Bead type & $\begin{array}{c}\text { Chitosan } \\
(\mathrm{g})\end{array}$ & $\begin{array}{c}\text { Glycine } \\
(\mathrm{g})\end{array}$ & $\begin{array}{c}\text { Glutamic } \\
\text { acid }(\mathrm{g})\end{array}$ & $\begin{array}{c}2 \% \\
\text { acetic acid } \\
(\mathrm{ml})\end{array}$ & $\begin{array}{c}\text { Glutaralde- } \\
\text { hyde } \\
(\%)\end{array}$ \\
\hline G1 & 1.0 & 0.5 & 0.5 & 40 & 3.13 \\
G2 & 1.0 & 0.5 & 0.5 & 40 & 6.25 \\
G3 & 1.0 & 0.5 & 0.5 & 40 & 12.5 \\
G4 & 1.0 & 0.5 & 0.5 & 40 & 25.0 \\
G5 & 0.8 & 0.5 & 0.5 & 40 & 12.5 \\
G6 & 1.2 & 0.5 & 0.5 & 40 & 12.5 \\
G7 & 1.0 & 0.4 & 0.6 & 40 & 12.5 \\
G8 & 1.0 & 0.6 & 0.4 & 40 & 12.5 \\
\hline
\end{tabular}


Drug loaded beads of same composition were also prepared separately by adding a known amount of CPM (150 $\mathrm{mg}, 200 \mathrm{mg}$ ) respectively to the chitosan, amino acid mixture before extruding into the $\mathrm{NaOH}$ - methanol solution.

\subsection{Swelling Studies}

Swelling behavior of chitosan beads (G1-G8) were studied in different $\mathrm{pH}$ (2.0 and 7.4) solutions. The percentage of swelling for each sample at time $t$ was calculated using the following formula-

Percentage of swelling $=\left\{\left(\mathrm{W}_{\mathrm{t}}-\mathrm{W}_{\mathrm{o}}\right) / \mathrm{W}_{\mathrm{o}}\right\} \times 100$

Where, $\mathrm{Wt}=$ weight of the beads at time $\mathrm{t}$ after emersion in the solution.

Wo $=$ weight of the dried beads.

\subsection{Drug Loading Assay}

Accurately weighed $(0.1 \mathrm{~g})$ drug loaded sample was kept in $100 \mathrm{ml}$ of $2 \%$ acetic acid for 48 hour. After centrifugation the CPM in the supernatant was assayed by spectrophotometer at $193.5 \mathrm{~nm}$.

\subsection{Drug Release Studies}

The drug release experiments were performed at $37^{\circ} \mathrm{C}$ under unstirred condition in acidic $(\mathrm{pH} 2.0)$ and basic ( $\mathrm{pH}$ 7.4) solution. Beads $(0.1 \mathrm{~g})$ containing known amount of the drug were added to the release medium $(30 \mathrm{ml})$. At pre decided intervals, samples of $2 \mathrm{ml}$ aliquots were withdrawn, filtered and assessed by recording the absorbance at $193.5 \mathrm{~nm}$. The cumulative CPM release was measured as a function of time.

\subsection{Kinetic Analysis of Drug Release}

A fair amount of work has been included in literature on kinetics of drug release [38,39]. A large number of modified release dosage forms contain some sort of matrix system and the drug dissolves from this matrix. The diffusion pattern of the drug is dictated by water penetration rate (diffusion controlled) and thus the Higuchi's equation [40] relationship applies

$$
\mathrm{M}_{\mathrm{t}} / \mathrm{M}_{\infty}=\mathrm{k} \mathrm{t}^{1 / 2}
$$

Where, $M_{t} / M_{\infty}$ is the fractional drug release at time $t$ and $\mathrm{k}$ is a constant related to the structural and geometric properties of the drug release system.

According to Higuchi's model, an inert matrix should provide a sustained drug release over a reasonable period of time and yield a reproducible straight line when the percentage of drug released is plotted versus the square root of time.

\subsection{Fourier Transform Infrared Spectra of IPN Beads}

FTIR spectra of IPN beads were recorded using a thermo
Nicolet Avatar 370 FT-IR spectrometer system using $\mathrm{KBr}$ pellets.

\subsection{Scanning Electron Microscopy (SEM)}

The shape and surface morphology of the beads were examined using FESEM QUANTA 200 FEG model "(FEI, the Netherlands make)" with operating voltage ranging from $200 \mathrm{~V}$ to $30 \mathrm{kV}$. FESEM micrographs were taken after coating the surfaces of bead samples with a thin layer of gold by using BAL-TEC-SCD-005 Sputter Coater (BAL-TEC AG, Balzers, Liechtenstein company, Germany) under argon atmosphere. SEM was used to perform textural characterization of full and cross sectioned IPN beads, magnification were applied to each sample in order to estimate the morphology and interior of the bead.

\subsection{X-Ray Diffraction (XRD)}

X-ray diffraction studies were performed by using Bruker AXS D8 Advance using CuK $\alpha$ Nickel filter and Copper as target at wavelength of $1.54 \AA$ with goniometer speed $2 \% \mathrm{~min}$.

\subsection{Thermal Analysis}

Thermal gravimetric analysis (TGA), Differential thermal gravimetric (DTG) and Derivative thermal analysis (DTA) were carried out simultaneously by using a Perkin Elmer (PYRIS Diamond) thermal analyzer model DSC-7, supplied by Perkin Elmer and the data was processed and analyzed by PYRIS muse measure and standard analysis software (V. 3.3U;. \#. 2002 Seiko instruments inc.). The sample was kept in alumina pan, the reference material was alumina powder and study was carried out at heating rate $10^{\circ} \mathrm{C} / \mathrm{min}$ under $200 \mathrm{ml} / \mathrm{min}$ flow rate of air or nitrogen atmosphere. Indium and gallium were used as standards for temperature calibration.

\section{Results and Discussion}

\subsection{Swelling Studies}

The effect of $\mathrm{pH}$, concentration of glutaraldehyde crosslinker, chitosan and aminoacid on swelling behaviour of chitosan-glutamic-glycine beads has been evaluated.

a) Effect of $p H$

Swelling studies to evaluate the effect of $\mathrm{pH}$ were carried out in solution of $\mathrm{pH} 2.0$ and $\mathrm{pH}$ 7.4. It was observed that percentage of swelling is higher in acidic solution ( $\mathrm{pH}$ 2.0) than in alkaline solution ( $\mathrm{pH}$ 7.4). We have also performed a comparative study for pure chitosan, chitosan-glycine, chitosan-glutamic acid and chitosan-glycine-glutamic acid systems [37] and observed that percentage of swelling for chitosan-glycine beads in 
acidic solution was found to be higher than in basic solution which is due to inherent hydrophobicity of the chitosan beads dominating at high $\mathrm{pH}$ value, thus preventing faster swelling in neutral and alkaline media but in case of chitosan-glutamic acid beads, percentage of swelling in basic solutions was found to be higher than in acidic solution which may be due to the presence of free carboxylic ends of the chitosan-glutamic acid IPN, more likely to be attacked by basic solution.

In case of chitosan-glycine-glutamic acid beads, their rate of swelling was also found to be higher at $\mathrm{pH} 2.0$ than chitosan-glutamic acid and chitosan-glycine beads but at $\mathrm{pH} \mathrm{7.4,} \mathrm{their} \mathrm{rate} \mathrm{of} \mathrm{swelling} \mathrm{were} \mathrm{intermediate}$ between chitosan-glutamic acid and chitosan-glycine beads. Thus it was concluded that over all rate of swelling was affected by glycine when chitosan-glycineglutamic acid beads were subjected to swelling studies.

b) Effect of glutaraldehyde

Swelling behaviour of crosslinked beads as a function of time in $\mathrm{pH} 2.0$ and $\mathrm{pH} 7.4$ solutions having different concentrations of glutaraldehyde are shown in "Figure-1(a)".

It was observed that the swelling rate of the crosslinked beads containing varying concentration of glutaraldehyde follows the order $\mathrm{G} 1>\mathrm{G} 2>\mathrm{G} 3>\mathrm{G} 4$ i.e. swelling rates increased with the decreased concentration of glutaraldehyde. When the cross linked beads are placed in the solution, the solution penetrates into the beads and the beads subsequently try to swell. Generally, the swelling process of the beads in $\mathrm{pH}<6$ involves the protonation of amino/imine groups in the beads and mechanically relaxation of the coiled polymeric chains. Initially during the process of protonation, amino/imine groups of the bead surface were protonized which led to dissociation of the hydrogen bonding between amino/imine group and other groups. Afterward, protons and counter ions diffused into the bead to protonate the amino/imine groups inside the beads and dissociating the hydrogen bonds $[41,42]$. It has been observed that the swelling rates are directly proportional to the degree of crosslinking. As the higher crosslink density results in higher strength of the beads and lower degree of swelling. Thus, the lowest swelling rate is observed in case of G4 beads.

\section{c) Effect of chitosan}

Effect of varying weight ratio of chitosan on swelling behaviour of crosslinked beads containing same quantity of glutaraldehyde have been studied in acidic $(\mathrm{pH} 2.0)$ and basic ( $\mathrm{pH}$ 7.4) solutions and results are presented in "Figure-1(b)". The percentage of swelling of the crosslinked beads having the same concentration of crosslinker decreases with increasing concentration of chitosan i.e. G5>G3>G6. It can be explained as the percentage of chitosan increased from G5 (44.4\%) to G6

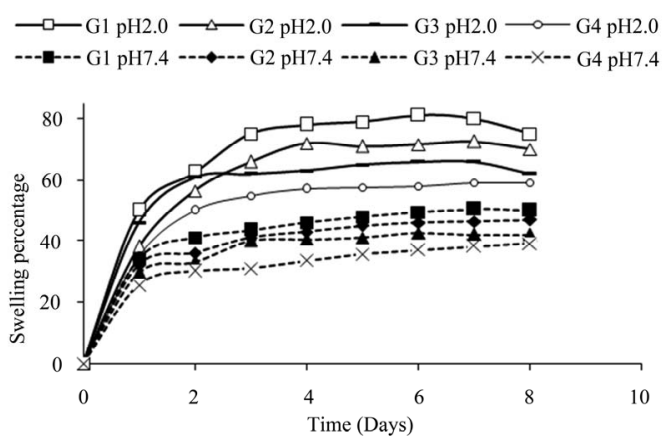

(a)

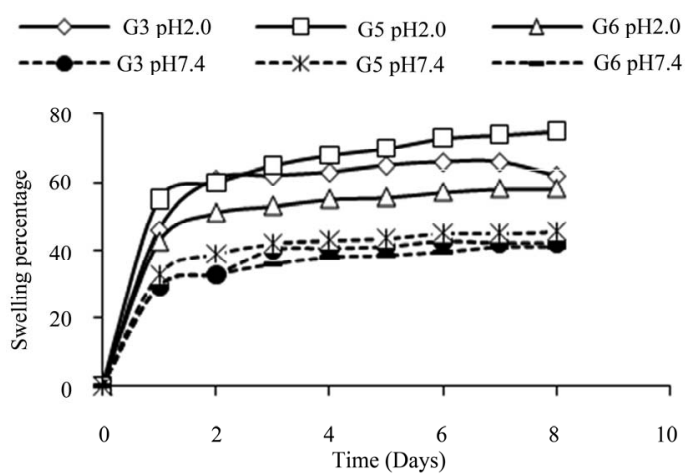

(b)
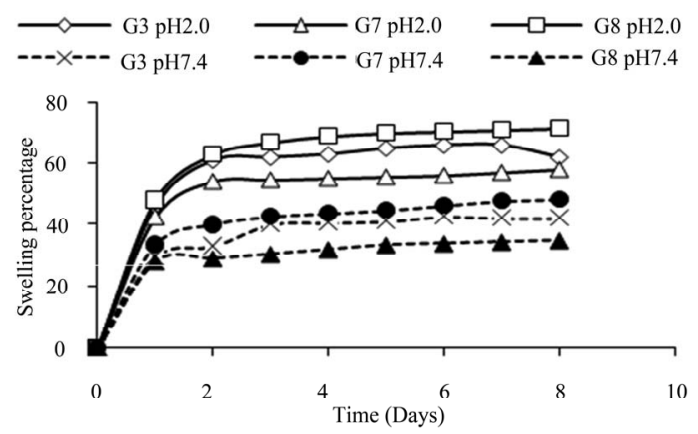

(c)

Figure 1. (a) Swelling behavior of crosslinked beads as a function of time in solution $\mathrm{pH} 2.0$ and $\mathrm{pH} 7.4$ at $37^{\circ} \mathrm{C}$ having different percentage of glutaraldehyde; (b) Swelling behavior of crosslinked beads as a function of time in solution pH 2.0 and $\mathrm{pH} 7.4$ at $37^{\circ} \mathrm{C}$ having different weight ratio of chitosan; (c) Swelling behavior of crosslinked beads as a function of time in solution $\mathrm{pH} 2.0$ and $\mathrm{pH} 7.4$ at $37^{\circ} \mathrm{C}$ having different weight ratio of amino acids.

(55.5\%) through G3 (50\%), the percentage of amino acids which act as a spacer decreased from G6 (55.5\%) to G5 (45.4\%) through G3 (50\%), the pore size of the beads decreases and the penetration of $\mathrm{pH}$ solution into the beads became difficult, which resulted in lesser degree of swelling further, swelling percentage was higher in acidic medium than in alkaline medium.

\section{d) Effect of amino acids}

The results obtained by changing in amino acids composition i.e. decrease in glutamic acid and increase in 
glycine concentration of crosslinked beads having same concentration of glutaraldehyde are given in "Figure-1(c)" have observed that the increase in concentration of glycine decreased the swelling percentage of crosslinked beads in basic solution i.e. $\mathrm{G} 8<\mathrm{G} 3<\mathrm{G} 7$ while increased in acidic solution (i.e. $\mathrm{G} 7<\mathrm{G} 3<\mathrm{G} 8$ ). It may be due to the different behaviour of glycine and glutamic acid as spacer arm in chitosan-amino acid beads towards different $\mathrm{pH}$ [37].

\subsection{Scanning Electron Microscopy Studies}

SEM micrographs of dried beads (G1-G8) and their surface morphology are shown in figure 2. It was concluded from "Figure 2" that the beads were nearly spherical or some what oval in shape this may be due to different composition of crosslinked beads due to which solution viscosity varied and beads varied in shape from spherical to oval or elongated as we know that solution with decreased viscosity can be extruded easily as spherical bead through a syringe. The approximate size of beads varied from 0.08 to $0.15 \mathrm{~mm}$. Cross linked chitosan amino acid beads (G1-G8) had rough, rubbery, fibrous and folded surfaces. With the highest concentration of cross linker, in case of G4 the chains come closer to each other and exhibit a regular, fibrous structure but with decreasing concentration of glutaraldehyde as in case of G3, G2 and G1 beads the structural morphology changes to layered and big fibrous bunches. Rubbery morphology is observed in case of lowest percentage of glutaraldehyde i.e in G1 beads. Although having same degree of crosslinker (i.e $12.5 \%$ glutaraldehyde) G5 and G6 beads constituting varied concentration of chitosan, while G7 and G8 beads constituting Varied concentration of glycine and glutamic acid also shown variation in surface morphology as shown in "Figure 2".

\subsection{Fourier Transform Infrared Spectra Studies}

"Figure 3(a)" shows the FTIR spectra of chitosan powder, glutamic acid, glycine and G1-G8 drug unloaded beads. FTIR spectra of chitosan powder curve has shown two peaks around $894 \mathrm{~cm}^{-1}$ and $1171 \mathrm{~cm}^{-1}$ corresponding to saccharide structure [43]. The observed peak at $1613 \mathrm{~cm}^{-1}$ can be assigned as amino absorption peak. The absorption peak for amide were observed at $1639 \mathrm{~cm}^{-1}$ and $1319 \mathrm{~cm}^{-1}$ and observed peak at $1384 \mathrm{~cm}^{-1}$ was assigned to $\mathrm{CH}_{3}$ symmetrical deformation mode $[44,45]$. A broad band appearing around $1083 \mathrm{~cm}^{-1}$ indicated the $>\mathrm{CO}-\mathrm{CH}_{3}$ stretching vibration of chitosan. Another broad band at $3450 \mathrm{~cm}^{-1}$ was due to the amine N-H symmetric stretching vibration which might be due to deacetylation of chitosan. Peak observed at $2924 \mathrm{~cm}^{-1}$ is typical of C-H stretching vibration. simultaneously the peak assigned for amino absorption at $1613 \mathrm{~cm}^{-1}$ in original chitosan broadened or disappered in cross linked beads and a new

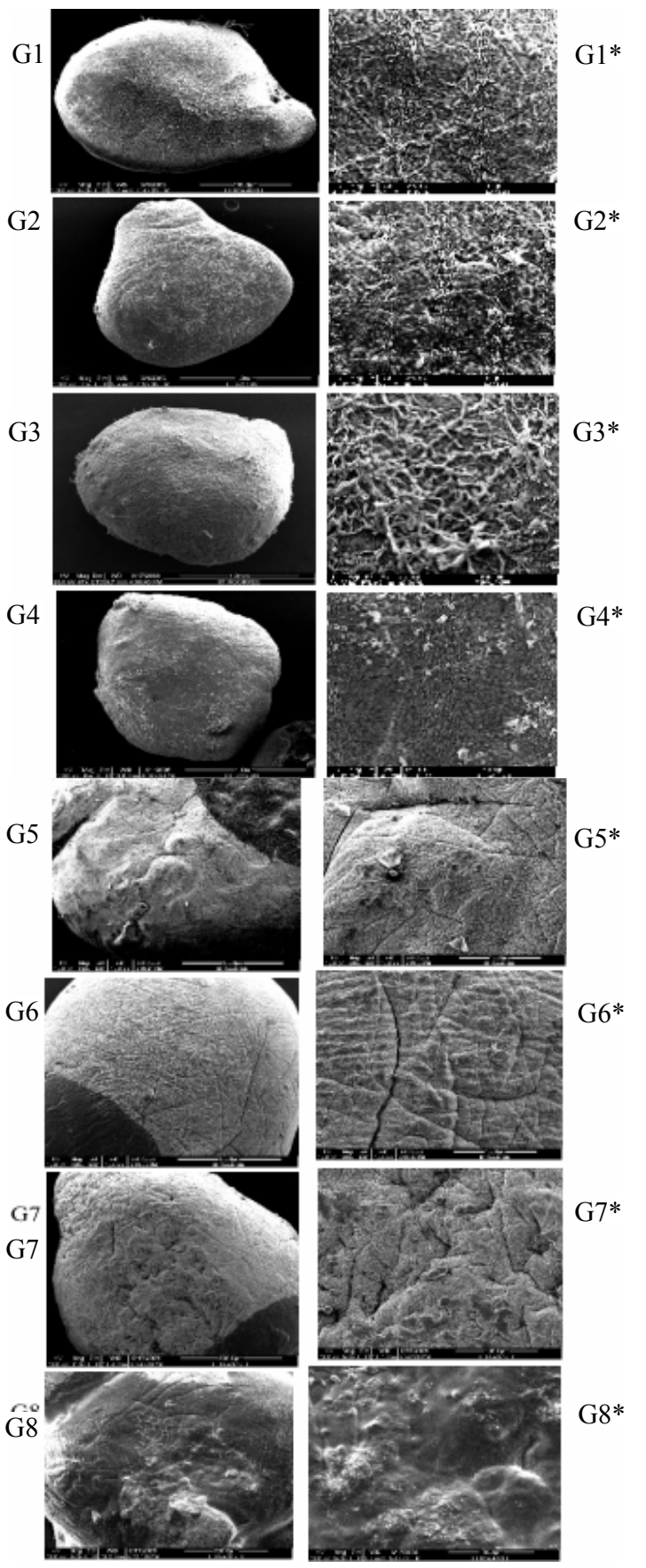

Figure 2. Scanning Electron Microscopy (SEM) photographs of crosslinked beads (G1-G8) and their magnified photographs showing surface morphology (G1*-G8*).

peak appearing at about $1567 \mathrm{~cm}^{-1}$ due to imine bond $(-\mathrm{C}=\mathrm{N}-)$ which was formed as a result of cross linking reaction between amino group in chitosan and aldehydic group in glutaraldehyde $[46,47]$ in curve G1-G8. However, this was due to the overlapping of peaks corresponding to $-\mathrm{NH}$ - stretching vibrations in $-\mathrm{NH}-\mathrm{COCH}_{3}$ at $1639 \mathrm{~cm}^{-1}$ of the original chitosan with that of imino- 


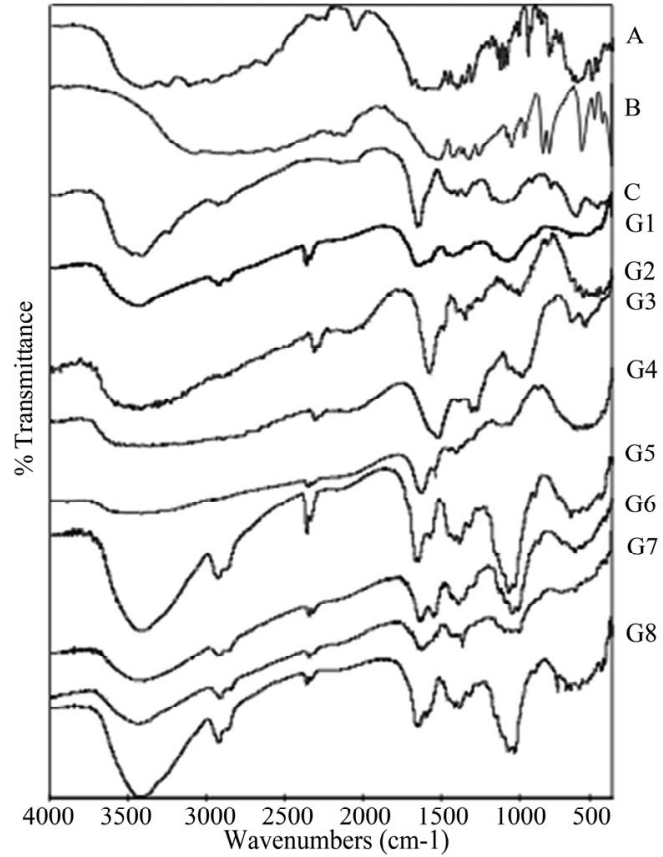

(a)

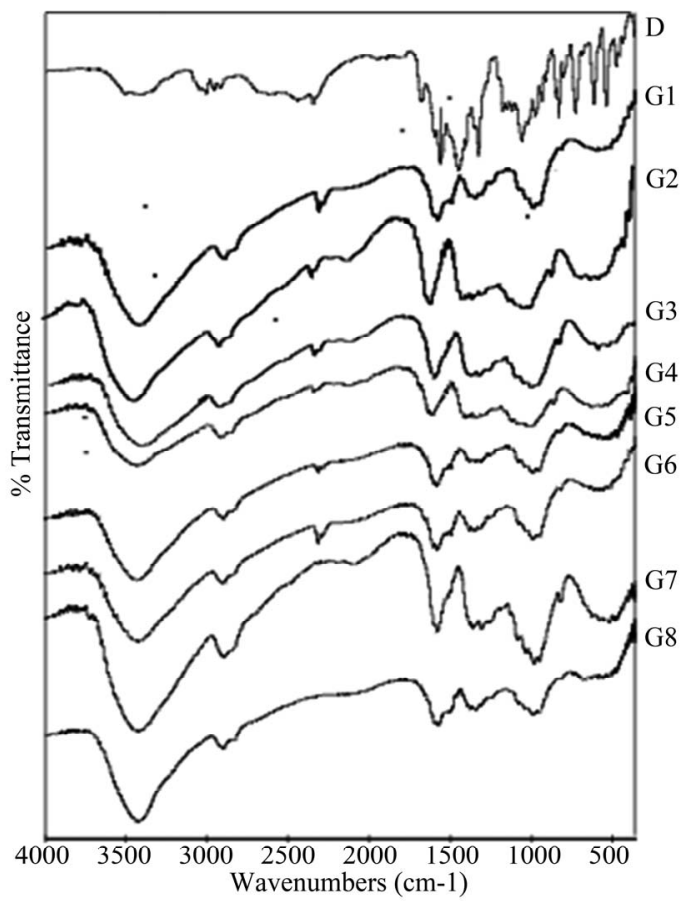

(b)

Figure 3. (a) FTIR spectra of glutamic acid (A), glycine (B), chitosan powder $(C)$ and drug unloaded crosslinked beads (G1-G8); (b) FTIR spectra of pure chlorpheniramine maleate (CPM) drug (D) and drug loaded crosslinked beads (G1-G8).

$(-\mathrm{C}=\mathrm{N}-)$ stretching at $1567 \mathrm{~cm}^{-1}$ of the newly formed structure between amino group of chitosan and aldehyde group of glutaraldehyde in G1-G8. A reaction taking palace in the formation of crosslink is as follows

----- $\mathrm{NH}_{2}+\mathrm{O}=\mathrm{HC}$----- $\rightarrow----\mathrm{N}=\mathrm{CH}-----$

Amino aldehyde imino

(chitosan) (glutaraldehyde) (cross link)

On increasing the glutaraldehyde concentration, the peak corresponding to $1567 \mathrm{~cm}^{-1}$ was sharpened and distinct in G4. All the curves G1 to G8 showed additional peaks of amino acid.

FTIR spectral data of drug loaded beads in "Figure 3(b)" were used to confirm the chemical stability of CPM in chitosan amino acid beads. FTIR spectra of pure CPM drug (curve D) and CPM loaded crosslinked beads (G1-G8) in "Figure 3(b)" were compared with drug unloaded crosslinked beads (G1-G8) in "Figure 3(a)". CPM has shown characteristic band at 2966 and 2917 $\mathrm{cm}^{-1}$ due to aliphatic $\mathrm{C}-\mathrm{H}$ stretching. The band at 1619 and $1588 \mathrm{~cm}^{-1}$ due to $\mathrm{C}=\mathrm{N}$ stretching vibration. While those of 1476 and $1432 \mathrm{~cm}^{-1}$ are due to aromatic $\mathrm{C}=\mathrm{C}$ stretching vibration. CPM has also shown characteristic band at around $864 \mathrm{~cm}^{-1}$ due to aromatic $\mathrm{C}-\mathrm{Cl}$ stretching. When drug was incorporated into the crosslinked chitosan-amino acid beads, along with all the characteristic band of the crosslinked chitosan and amino acids, additional band have appeared due to the presence of CPM in the matrix. It indicates that CPM has not undergone any chemical change with in the beads.

\subsection{X-Ray Diffraction Studies}

$\mathrm{X}$ ray diffractograms of chitosan, glycine, glutamic acid and drug unloaded beads (G1-G8) are presented in "Figure 4(a)" and also of pure CPM drug and drug loaded beads (G1-G8) are shown in “Figure 4(b)”. XRD peaks depends on the crystal size. The diffraction pattern of pure chitosan has the characteristic peaks at $2 \theta$ of 12 to 16,20 and 29. All the drug unloaded beads (G1 to G8) in "Figure 4(a)" show the similar peaks as that of chitosan. CPM drug has shown characteristic intense peaks at $2 \theta$ of 12 to 35 , however, these peaks are not observed in CPM loaded beads (G1-G8) in "Figure 4(b)" but instead, the diffractograms of both the drug loaded and drug unloaded beads are almost identical, indicating the amorphous dispersion of drug after entrapment into polymeric chitosan-amino acid beads. No crystal of drug were found in the drug loaded beads upto the detection limit [48,49].

\subsection{Thermal Analysis}

Thermal gravimetric analysis (TGA) experiment were carried out on chitosan, glutamic acid, glycine and cross linked drug unloaded beads [G1-G8] and the curve obtained are presented in "Figure 5(a)" which clearly shows that approximately $10 \%$ weight loss by chitosan 


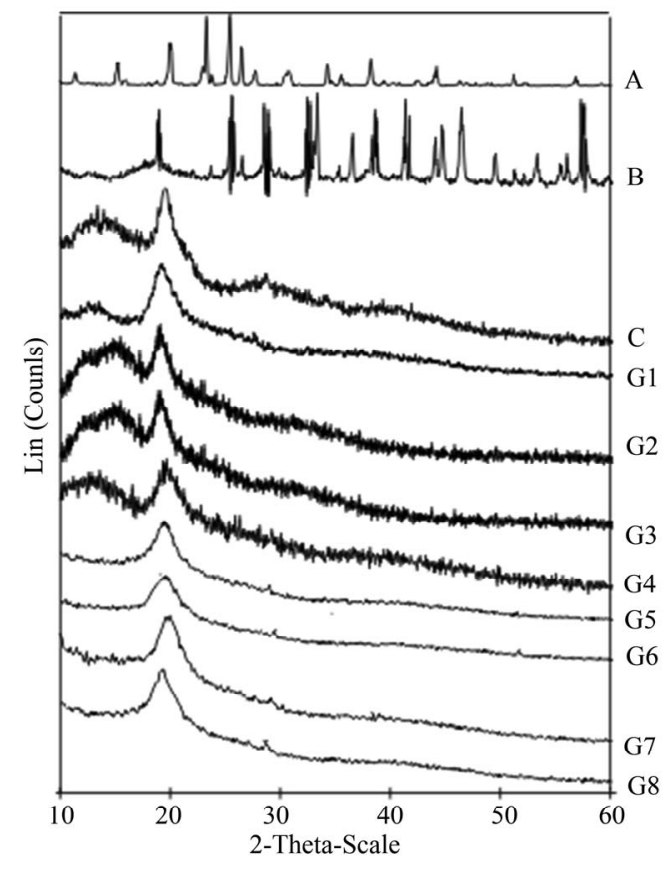

(a)

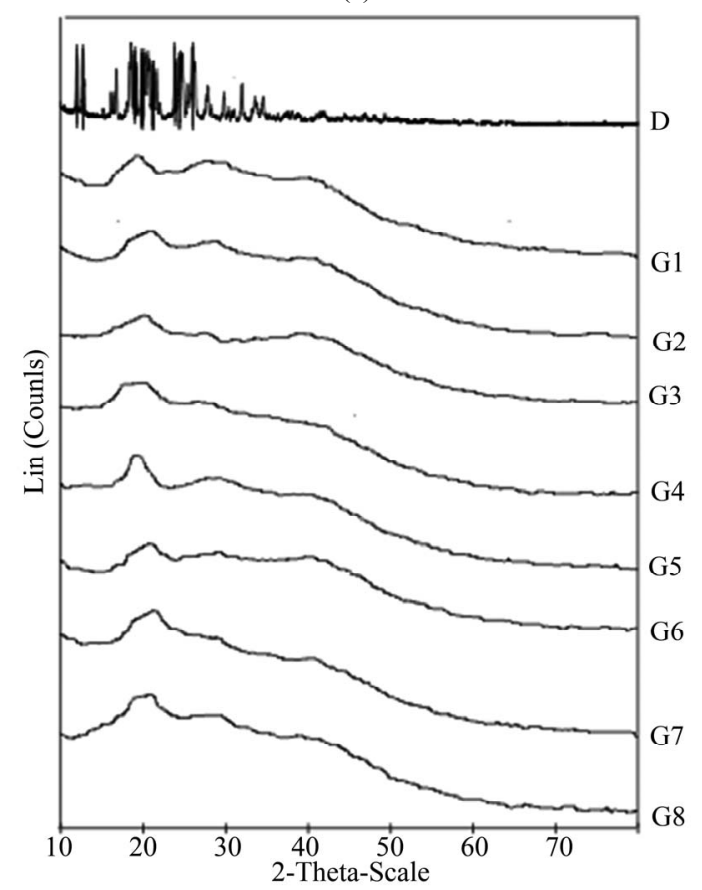

(b)

Figure 4. (a) X-ray Diffraction (XRD) graphs of glutamic acid (A), glycine (B), chitosan powder (C) and drug unloaded crosslinked beads (G1-G8); (b) X-ray Diffraction (XRD) graphs of pure chlorpheniramine maleate (CPM) drug (D) and drug loaded crosslinked beads (G1-G8).

powder (curve A) below $100^{\circ} \mathrm{C}$ due to loss of free water. After this, weight loss remains constant up to $249^{\circ} \mathrm{C}$. A sudden weight loss is observed after $249^{\circ} \mathrm{C}$ and the total weight loss at $400^{\circ} \mathrm{C}$ is about $60 \%$, while as the crosslinking density increased from G1 to G4 the weight loss percent decreased continuously upto $47 \%$ at $400^{\circ} \mathrm{C}$. This shows that cross linking of chitosan with glutaraldehyde increases its thermal stability.

TG curves for CPM model drug (curve D) and drug loaded crosslinked beads (G1-G8) are shown in "Figure 5(b)". CPM drug lost about $67 \%$ weight between $208^{\circ} \mathrm{C}$ and $274^{\circ} \mathrm{C}$ (curve D) which was due to the decomposition of drug above its melting point. Melting point of $\mathrm{CPM}$ is $134^{\circ} \mathrm{C}$ and such a huge loss in weight was not shown by drug loaded beads G1-G8 containing drug. This concluded that the drug is quite stable with in the beads.

Differential thermal gravimetric (DTG) thermograms of pure chitosan, glutamic acid, glycine and cross linked beads G1-G8 are presented in "Figure 6(a)". These indicated the rate of weight loss for chitosan powder was highest at $290^{\circ} \mathrm{C}$ and cross linked chitosan beads showed lesser rate of weight loss between 222 to $271^{\circ} \mathrm{C}$. On comparing G1-G4 beads it can be seen that G4 beads were found to be most stable as they lose weight at minimum rate approximately $371 \mu \mathrm{g} / \mathrm{min}$ at $255^{\circ} \mathrm{C}$ as compared to $\mathrm{G} 1$ beads $(3.47 \mathrm{mg} / \mathrm{min})$ at $245^{\circ} \mathrm{C}$, this concluded that crosslinking made the beads more stable. Variation of chitosan concentration (G5 to G6 beads) and amino acid composition (G7 and G8 beads) give almost equally stable as that of G3 beads.

DTG curves for CPM drug and drug loaded crosslinked beads (G1-G8) are shown in "Figure 6(b)". Curve D for pure CPM drug have peaks for weight loss at $134^{\circ} \mathrm{C}, 207^{\circ} \mathrm{C}$ and $256^{\circ} \mathrm{C}$. The comparison of drug unloaded beads G1-G8 in "Figure 6(a)" and drug loaded beads G1-G8 in "Figure 6(b)" showed almost similar peaks with approximate same rate of weight lost also proved equally drug stability in the polymeric matrix Containing drug.

Derivative thermal analysis (DTA) thermograms for pure chitosan, glutamic acid, glycine and cross linked drug unloaded beads (G1-G8) are presented in "Figure 7(a)". Thermograms for chitosan powder showed one endothermic peak at $65^{\circ} \mathrm{C}$ due to loss of free water and one exothermic peak at $296^{\circ} \mathrm{C}$ due to chemical transformation. Glutamic acid gives two and glycine gives one endothermic peak in their thermo grams. While in case of (G1-G8) beads only one exothermic peak is observed. It was concluded that crosslinked chitosan-glycineglutamic acid G1-G8 beads are the equally stable.

DTA thermo grams for pure CPM drug and drug loaded beads G1-G8 are represented in "Figure 7(b)". In case of CPM drug (curve D) one endothermic peak and one exothermic peak were observed, one at $134^{\circ} \mathrm{C}$ which corresponds to melting process and other at $294^{\circ} \mathrm{C}$ to 


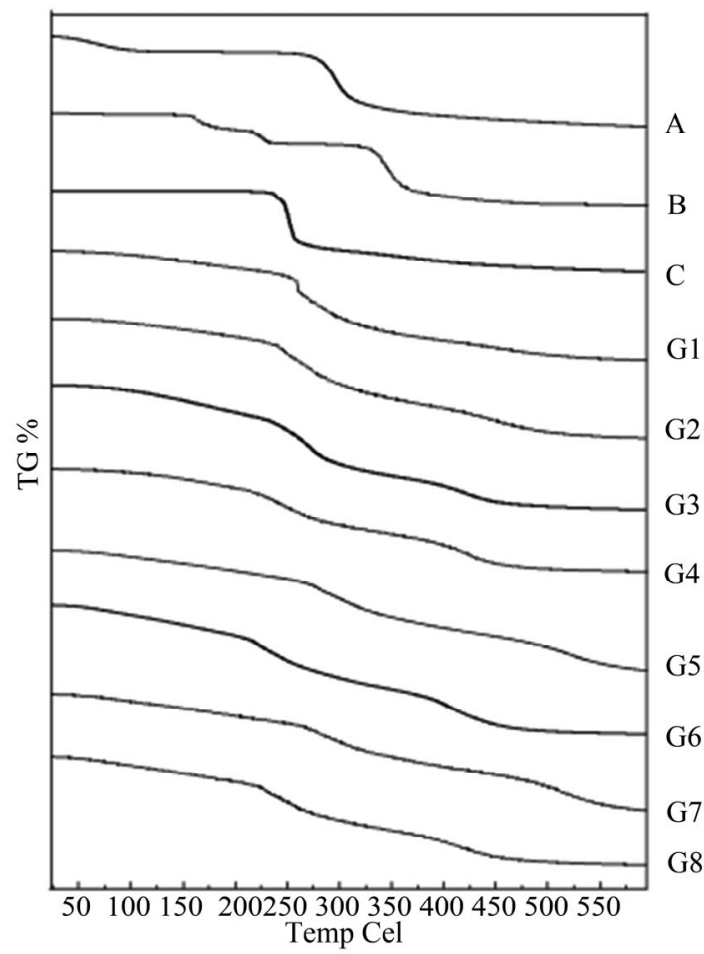

(a)

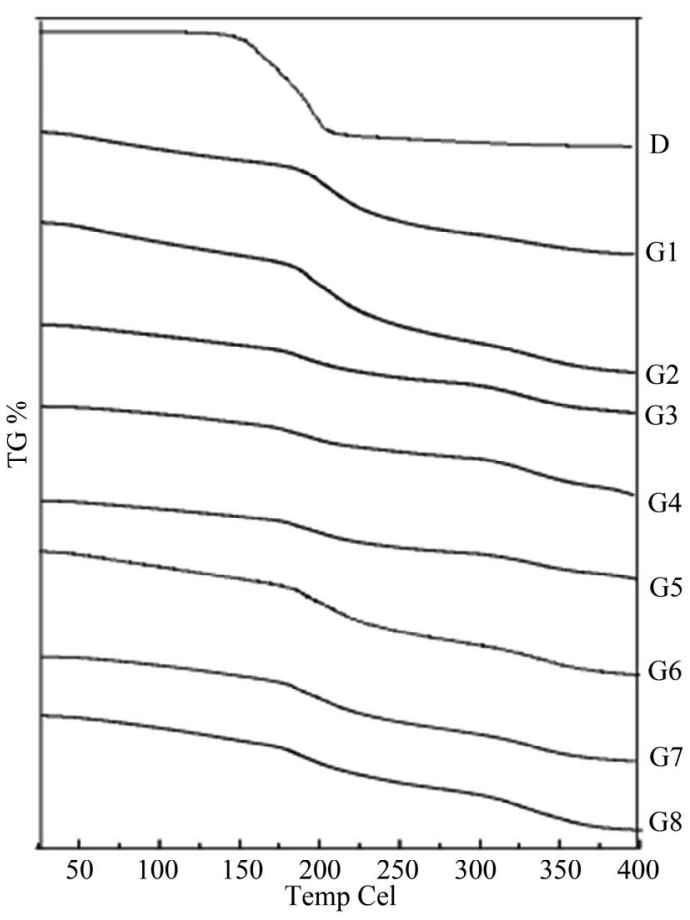

(b)

Figure 5. (a) Thermal gravimetric analysis (TGA) curves for chitosan powder (A), glutamic acid (B), glycine (C) and drug unloaded crosslinked beads (G1-G8); (b) Thermal gravimetric analysis (TGA) curves for pure chlorpheniramine maleate (CPM) drug (D) and drug loaded crosslinked beads (G1-G8).

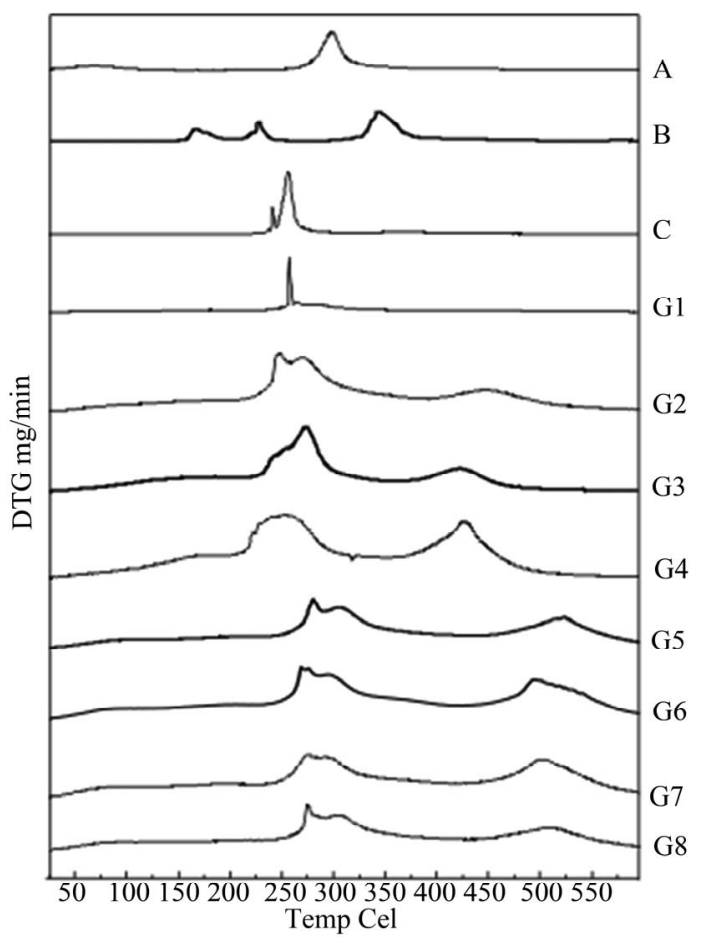

(a)

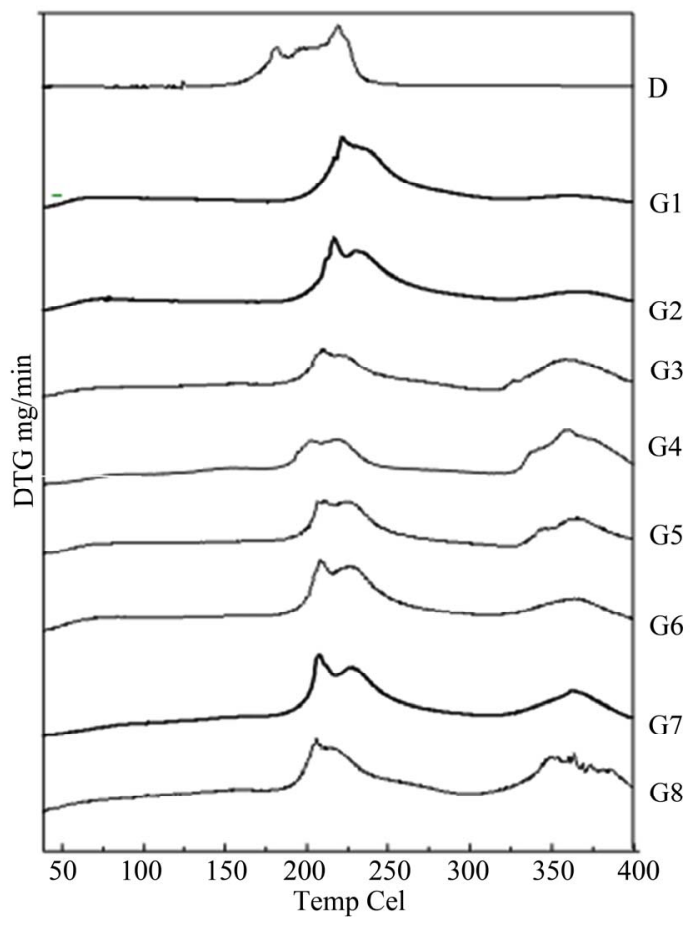

(b)

Figure 6. (a) Differential thermal gravimetric (DTG) curves for chitosan powder (A), glutamic acid (B), glycine (C) and drug unloaded crosslinked beads (G1-G8); (b) Differential thermal gravimetric DTG) curves for chlorpheniramine maleate (CPM) Jdrug (D) and drug loaded crosslinked beads (G1-G8). 


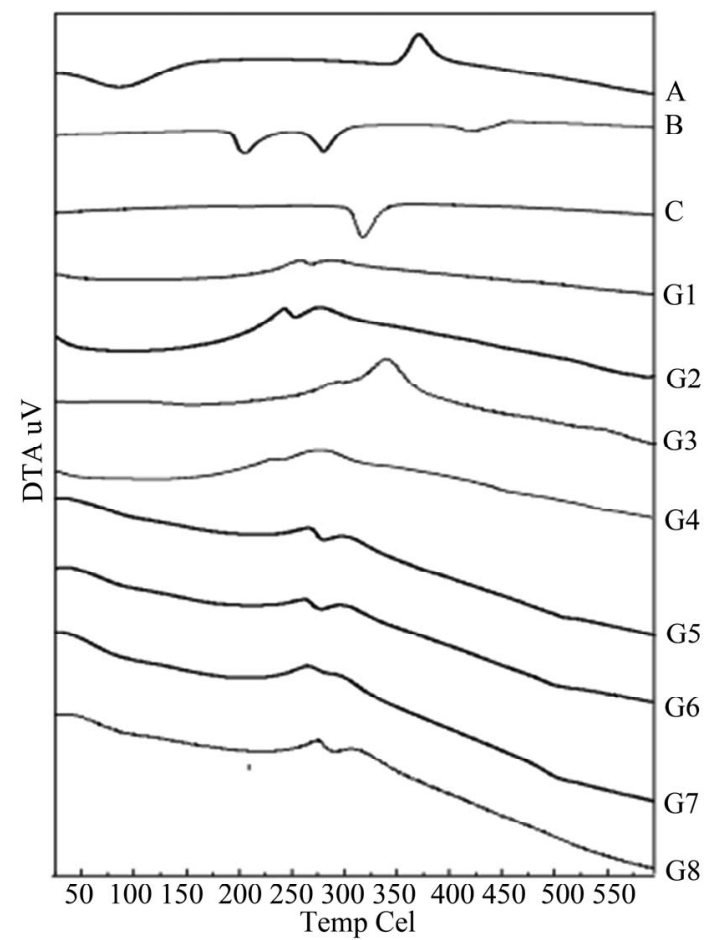

(a)

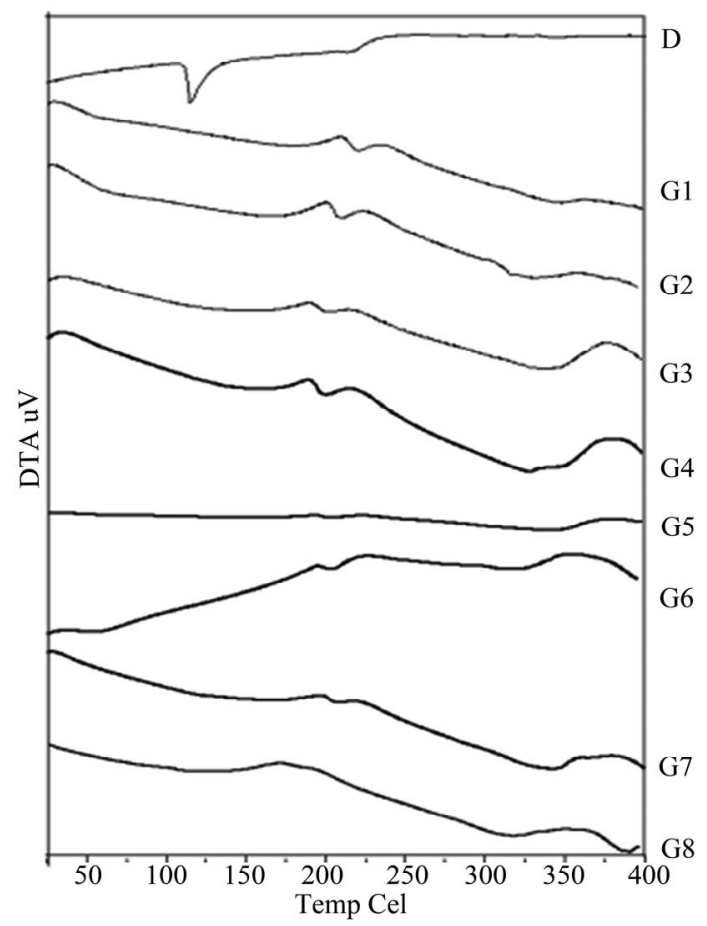

(b)

Figure7. (a) Derivative thermal analysis (DTA) curves for chitosan powder (A), glutamic acid (B), glycine (C) and drug unloaded crosslinked beads (G1-G8); (b) Derivative thermal analysis (DTA) curves for chlorpheniramine maleate (CPM) drug (D) and drug loaded crosslinked beads (G1-G8). chemical transformation. Drug loaded beads (G1-G8) showed almost similar thermo grams in which no peaks were observed at $134^{\circ} \mathrm{C}$ and $294^{\circ} \mathrm{C}$ indicating the amorphous dispersion of drug into the beads $[50,51]$.

\subsection{Drug Release Studies}

Drug loading assay studies shows that the beads loaded with $150 \mathrm{mg}$ and $200 \mathrm{mg}$ of CPM respectively actually released $78 \mu \mathrm{g}$ and $142 \mu \mathrm{g}$ of drug respectively on biodegradation of $0.1 \mathrm{~g}$ of beads in $100 \mathrm{ml}$ of 2 percent acetic acid after 48 hours. "Figure 8(a), 8(b) and 8(c)" shows the release profile of CPM from chitosan beads loaded (78 $\mu \mathrm{g}$ of drug) at various time intervals in acidic $(\mathrm{pH} 2.0)$ and basic $(\mathrm{pH} 7.4)$ solutions at $37^{\circ} \mathrm{C}$. There was a burst release initially for the first hour in both acidic and basic media followed by a moderate release for next four hours and finally an almost constant release of CPM from the matrix for the studied period of 48 hour. The amount and percentage of drug released followed the order of swelling of beads. It is because the release rate depends on swelling of the beads. It was noticed that drug release was $\mathrm{pH}$ dependent as the amount and percentage of drug released were much higher in acidic medium than in alkaline medium in case of G1 to G8 beads. This can be explained by the fact that the release of drug due to diffusion through the swollen beads depends mainly on the percentage of swelling of beads. Initially the burst release of drug was observed due to the fast penetration of the solvent into the crosslinked beads. After few hours, a steady state was reached, due to the equilibrium concentration gradient and then a constant drug release was observed. At pH 7.4 there is less swelling thus drug entrapped in the beads could not be released easily, however, at $\mathrm{pH} 2.0$ the beads were swollen to a higher percentage, leading to faster release of drug.

It was observed in "Figure 8(a)" that the drug release rate increases with the decrease in crosslink density. This may be due to the fact that the diffusion of drug from IPN depends on the pore size of the polymer network which will decrease with increase in degree of crosslinking.

The release profile of CPM drug has been checked for the beads having varying amount of chitosan for the same amount of amino acids and glutaraldehyde (12.5\%). It was observed from "Figure 8(b)" that the G5 beads having smaller weight of chitosan gave higher release rates and slowest release rate was observed in case of G6 beads containing higher concentration of chitosan. This may be due to containing more chitosan, the amount of available amino acids acting as spacer group became low and there was possibility of formation smaller mesh size volume, which in turn might decrease the rate of swelling as well as drug release. 

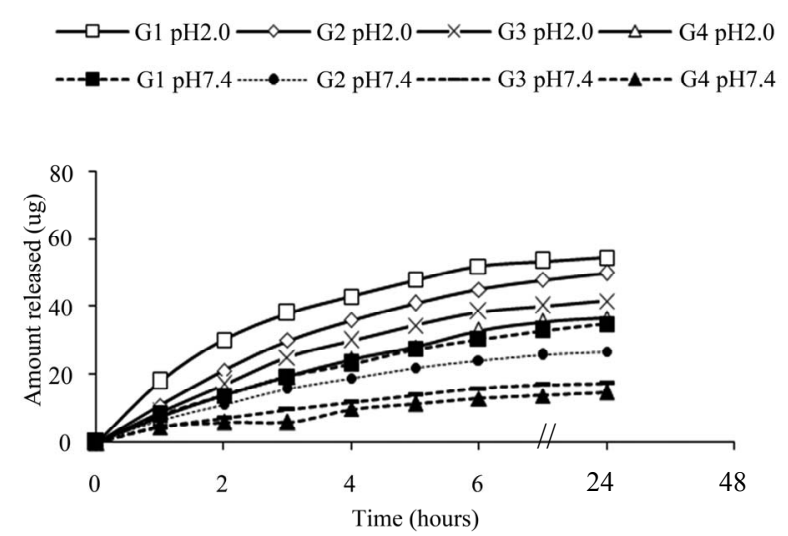

(a)
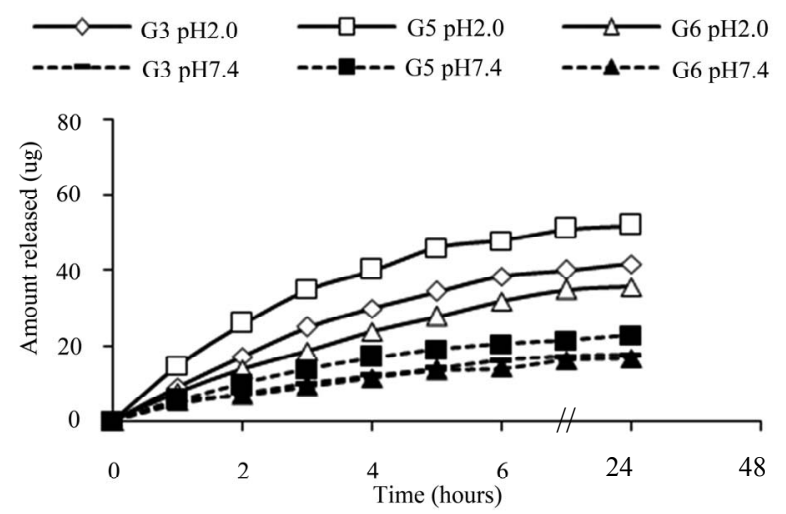

(b)
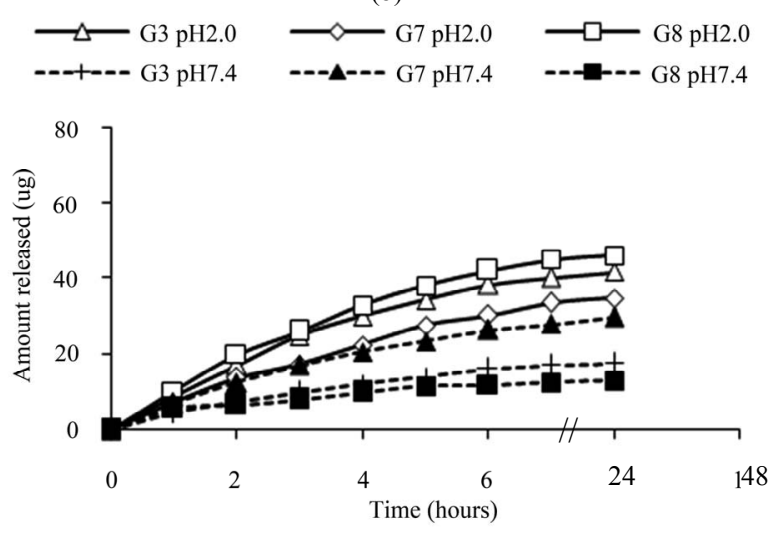

(c)

Figure 8. (a) Release of chlorpheniramine maleate (CPM) from $78 \mu \mathrm{g}$ CPM loaded beads vs time in solution $\mathrm{pH} 2.0$ and $\mathrm{pH} 7.4$ at $37^{\circ} \mathrm{C}$ having different percentage of glutaraldehyde; (b) Release of chlorpheniramine maleate (CPM) from $78 \mu \mathrm{g}$ CPM loaded beads vs time in solution pH 2.0 and $\mathrm{pH} 7.4$ at $37^{\circ} \mathrm{C}$ having different weight ratio of chitosan; (c) Release of chlorpheniramine maleate (CPM) from $78 \mu \mathrm{g}$ CPM loaded beads vs time in solution $\mathrm{pH} 2.0$ and $\mathrm{pH} 7.4$ at $37^{\circ} \mathrm{C}$ having different weight ratio of amino acid.

The drug release rates of CPM drug have also been studies for the beads having different composition of amino acids (i.e. glycine and glutamic acid) and results shown in "Figure 8(c)". It was observed that on increasing the amount of glycine or decreasing the amount of glutamic acid in G8 bead increased the rate of drug release in acidic solution while decreased in basic solution. These results are quite similar to the results observed for swelling rate. This may be due to the different chemical structures of glycine and glutamic acid. The reason may be due to the presence of two carboxylic ends of the glutamic acid. Since carboxylic group is more susceptible to be attacked by the basic solution, the drug release in the acidic medium was less due to the interaction of acidic solution with the polar group of glutamic acid in beads. In case when glycine and glutamic acid both amino acid are used for as spacer arm group within the chitosan beads, the amount and percentage of drug release were higher in acidic medium than in basic medium. This concluded that glycine showed dominant effect over glutamic acid and over all effect was governed by glycine.

To check the reproducibility of the result, the release profile of CPM from the chitosan beads loaded with higher amounts of drug (142 $\mu \mathrm{g}$ of drug loaded beads) has also been studied in acidic $\mathrm{pH} 2.0$ and basic $\mathrm{pH} 7.4$ media as shown in "Figure 9(a), 9(b) and 9(c)". The release pattern of the drug loaded beads has been found to be similar irrespective of the amount of the drug loaded. These observations have suggested that the total amount of drug release from the chitosan beads has increased with the increase in concentration of CPM. However, the percentage of CPM released from the beads loaded with a higher amount of drug was found to be lower in comparison to the beads loaded with a lower amount. This concluded that the mechanism of the drug release due to the diffusion through swollen beads depends on the percentage of swelling of beads.

\subsection{Kinetic Analysis of Drug Release}

In order to have an insight into the mechanism of drug release behaviour Higuchi's model were best fitted into the kinetic data of drug release. Linear plots of percent cumulative amount release versus square root of time for IPN beads constituting $78 \mu \mathrm{g}$ CPM drug are shown in “Figure 10(a), 10(b) and 10(c)"and similar linear plots are also shown in "Figure 11(a), 11(b) and 11(c)" for IPN beads constituting $142 \mu \mathrm{g}$ CPM drug which demonstrating that the release from the crosslinked polymeric microsphere matrix is diffusion controlled and obeys the Higuchi's model [52]. The constant k, presented in "Table-2" was calculated from the slope of the linear portion of plot of percentage of cumulative drug released versus the square root of time. The value of $\mathrm{k}$ for the release process have been found to be lower in solution of $\mathrm{pH}$ 7.4 than in solution of $\mathrm{pH} 2.0$. However, the values were smaller which indicate mild interaction between the drug 
Table 2. Results of drug release mechanism by fitting data in Higuchi's model for CPM loaded beads.

\begin{tabular}{|c|c|c|c|c|c|c|c|c|c|c|c|c|}
\hline \multirow{3}{*}{$\begin{array}{l}\text { Beads } \\
\text { type }\end{array}$} & \multicolumn{6}{|c|}{$\begin{array}{c}\mathrm{pH} 2.0 \\
\text { CPM loaded beads with }\end{array}$} & \multicolumn{6}{|c|}{$\begin{array}{c}\mathrm{pH} \mathrm{7.4} \\
\text { CPM loaded beads with }\end{array}$} \\
\hline & \multicolumn{3}{|c|}{$78 \mu g$} & \multicolumn{3}{|c|}{$142 \mu g$} & \multicolumn{3}{|c|}{$78 \mu g$} & \multicolumn{3}{|c|}{$142 \mu g$} \\
\hline & $\mathrm{k}$ & S.D. & $\mathrm{R}$ & $\mathrm{k}$ & S.D. & $\mathrm{R}$ & $\mathrm{k}$ & S.D. & $\mathrm{R}$ & $\mathrm{k}$ & S.D. & $\mathrm{R}$ \\
\hline G1 & 0.30 & \pm 0.017 & 0.99 & 0.205 & \pm 0.008 & 0.99 & 0.20 & \pm 0.019 & 0.99 & 0.13 & \pm 0.008 & 0.98 \\
\hline G2 & 0.31 & \pm 0.035 & 0.99 & 0.19 & \pm 0.009 & 0.99 & 0.16 & \pm 0.015 & 0.99 & 0.095 & \pm 0.005 & 0.99 \\
\hline G3 & 0.26 & \pm 0.030 & 0.99 & 0.20 & \pm 0.015 & 0.99 & 0.10 & \pm 0.009 & 0.99 & 0.083 & \pm 0.008 & 0.99 \\
\hline G4 & 0.22 & \pm 0.025 & 0.99 & 0.195 & \pm 0.015 & 0.99 & 0.08 & \pm 0.008 & 0.95 & 0.073 & \pm 0.009 & 0.99 \\
\hline G5 & 0.30 & \pm 0.026 & 0.99 & 0.19 & \pm 0.005 & 0.99 & 0.14 & \pm 0.014 & 0.99 & 0.097 & \pm 0.009 & 0.99 \\
\hline G6 & 0.22 & \pm 0.024 & 0.99 & 0.19 & \pm 0.015 & 0.99 & 0.085 & \pm 0.005 & 0.99 & 0.081 & \pm 0.009 & 0.99 \\
\hline G7 & 0.20 & \pm 0.022 & 0.99 & 0.175 & \pm 0.014 & 0.99 & 0.17 & \pm 0.016 & 0.99 & 0.12 & \pm 0.009 & 0.99 \\
\hline G8 & 0.28 & \pm 0.031 & 0.99 & 0.20 & \pm 0.011 & 0.99 & 0.06 & \pm 0.005 & 0.98 & 0.069 & \pm 0.008 & 0.98 \\
\hline
\end{tabular}

$-\mathrm{G} 1 \mathrm{pH} 2.0 \longrightarrow \mathrm{G} 2 \mathrm{pH} 2.0 \longrightarrow \mathrm{G} 3 \mathrm{pH} 2.0 \longrightarrow \mathrm{G} 4 \mathrm{pH} 2.0$

---G1 pH7.4 ---๑--- G2 pH7.4 ------- G3 pH7.4 ---*--- G4 pH7.4

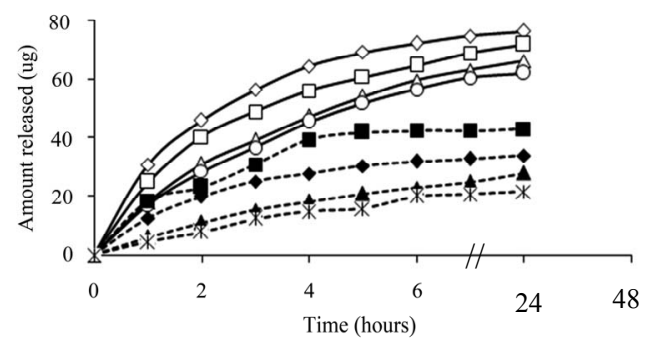

(a)

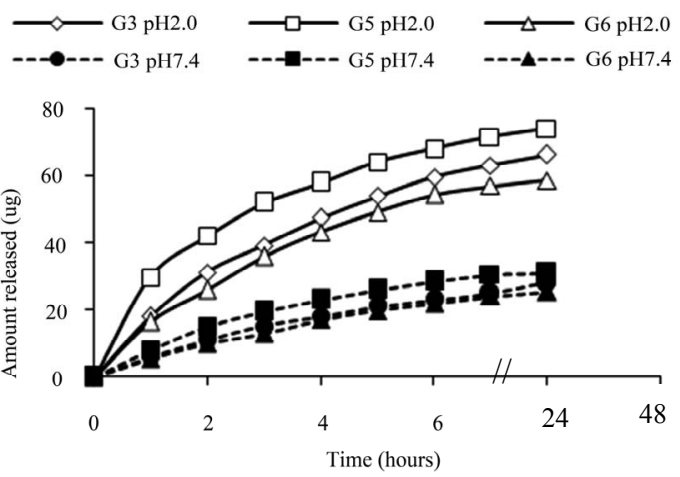

(b)
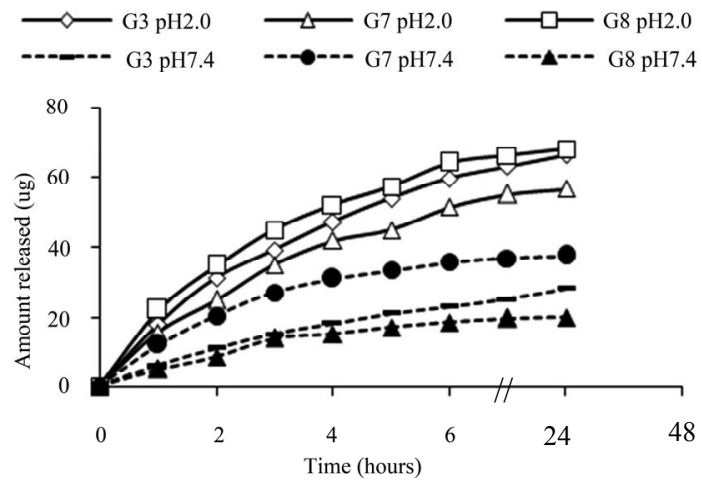

(c)
Figure 9. (a) Release of chlorpheniramine maleate (CPM) from $142 \mu \mathrm{g}$ CPM loaded bead vs time in solution $\mathrm{pH} 2.0$ and $\mathrm{pH} 7.4$ at $37^{\circ} \mathrm{C}$ having different percentage of glutaraldehyde; (b) Release of chlorpheniramine maleate (CPM) from $142 \mu \mathrm{g}$ CPM loaded bead vs time in solution $\mathrm{pH} 2.0$ and $\mathrm{pH} 7.4$ at $37^{\circ} \mathrm{C}$ having different weight ratio of chitosan; (c) Release of chlorpheniramine maleate (CPM) from 142 $\mu g$ CPM loaded bead vs time in solution pH 2.0 and pH 7.4 at $37^{\circ} \mathrm{C}$ having different weight ratio of amino acid.

and polymeric matrices [53,54].

\section{Conclusion}

The observations of the present study have shown that

- $\mathrm{G} 1 \mathrm{pH} 2$ - $22 \mathrm{pH}_{2} \quad \Delta \quad \mathrm{G} 3 \mathrm{pH} 2 \quad$ - $44 \mathrm{pH} 2$

- $\mathrm{G} 1 \mathrm{pH} 7.4$ - $\mathrm{G} 2 \mathrm{ph} 7.4$ • $\mathrm{G} 3 \mathrm{pH} 7.4$ - $\mathrm{G} 4 \mathrm{pH} 7.4$

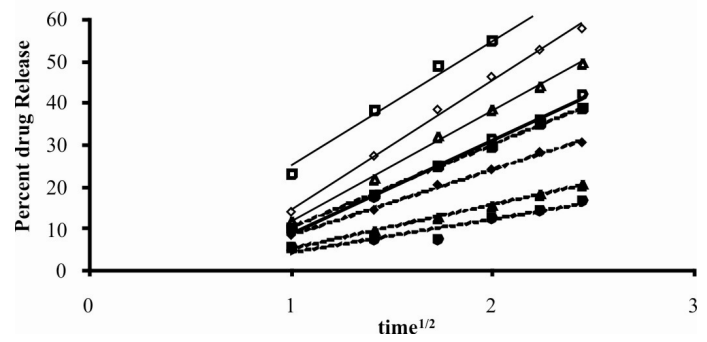

(a)

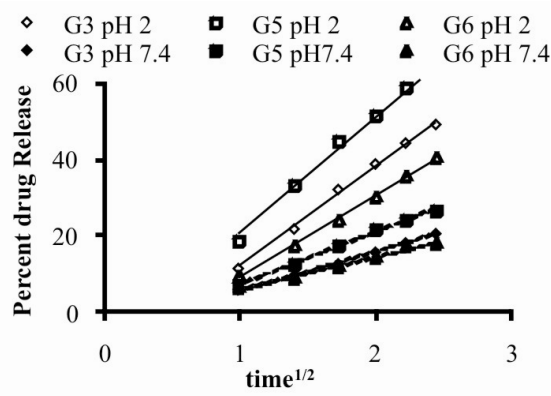

(b) 


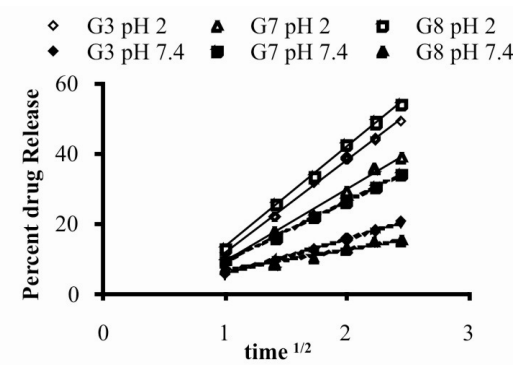

(c)

Figure 10. (a) Plots showing drug release profile from $78 \mathrm{\mu g}$ chlorpheniramine maleate (CPM) loaded beads in solution pH 2.0 and pH 7.4 by fitting the Higuchi's equation having different percentage of glutaraldehyde; (b) Plots showing drug release profile from $78 \mu \mathrm{g}$ chlorpheniramine maleate (CPM) loaded beads in solution pH 2.0 and pH 7.4 by fitting the Higuchi's equation having different weight ratio of chitosan; (c) Plots showing drug release profile from 78 $\mathrm{g}$ chlorpheniramine maleate (CPM) loaded beads in solution pH 2.0 and pH 7.4 by fitting the Higuchi's equation having different weight ratio of amino acid

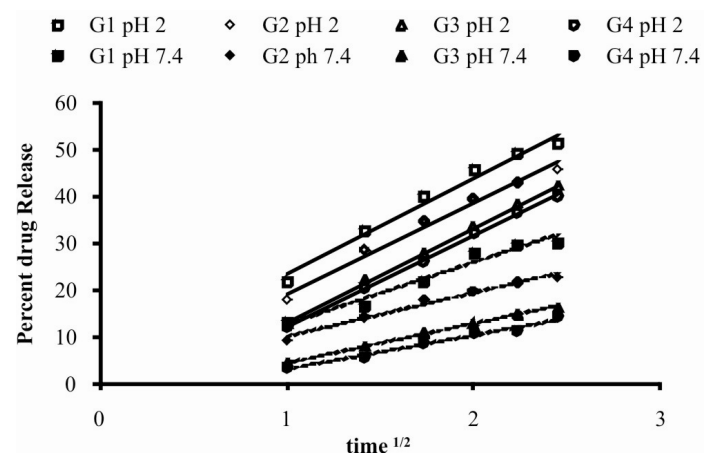

(a)

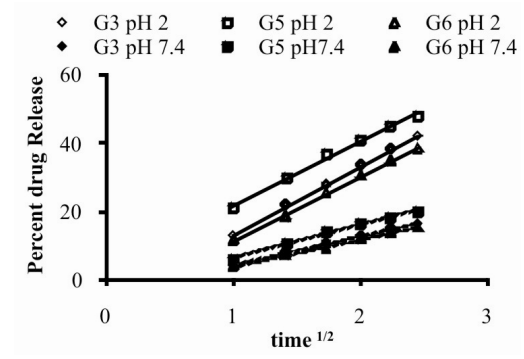

(b)

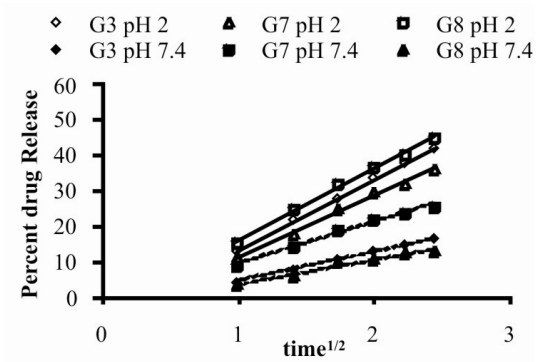

(c)

Figure 11. (a) Plots showing drug release profile from 142 ug chlorpheniramine maleate (CPM) loaded beads in solution pH 2.0 and pH 7.4 by fitting the Higuchi's equation. having different percentage of glutaraldehyde; (b) Plots showing drug release profile from $142 \mu \mathrm{g}$ chlorpheniramine maleate (CPM) loaded beads in solution pH 2.0 and pH 7.4 by fitting the Higuchi's equation having different weight ratio of chitosan; (c) Plots showing drug release profile from $142 \mu$ g chlorpheniramine maleate (CPM) loaded beads in solution pH 2.0 and pH 7.4 by fitting the Higuchi's equation having different weight ratio of amino acid.

chitosan-glycine-glutamic acid beads posses a $\mathrm{pH}$ dependent swelling behavior. It can be used successfully for the formulation of controlled drug delivery devices. They have optimum entrapping capacity for the studied drugs and provide a sustained release of drugs for extended periods which make them appropriate for delivery of drug at a controlled rate.

\section{Acknowledgement}

Authors are thankful to Prof. B. Gupta, Bioengineering Laboratory, Textile Department, IIT, Delhi for gifting chitosan sample.

\section{REFERENCES}

[1] J. Jagur-Grodzinski, "Biomedical Application of Functional Polymers," Reactive Functional Polymers, Vol. 39, 1999, pp. 99-138. doi:10.1016/S1381-5148(98)00054-6

[2] K. E. Uhrich, S. M. Cannizzaro, R. S. Langer and K. M. Shakesheff, "Polymeric Systems for Controlled Drug Release," Chemical Reviews, Vol. 99, No. 11, 1999, pp. 3181-3198. doi:10.1021/cr940351u

[3] V. Kumar and S. H. Kothari, "Effect of Compressional Force on the Crystallinity of Directly Compressible Cellulose Excipients," International Journal of Pharmaceutics, Vol. 177, No. 2, 1999, pp. 173-182. doi:10.1016/S0378-5173(98)00340-8

[4] M. George and T. E. Abraham, "Polyionic Hydrocolloids for the Intestinal Delivery of Protein Drugs, Alginate and Chitosan - A Review," Journal of Controlled Release, Vol. 114, No. 1, 2006, pp. 1-14. doi:10.1016/j.jconrel.2006.04.017

[5] Q. Gan, T. Wang, C. Cochrane and P. McCarron, "Modulation of Surface Charge Particle Size and Morphological Properties of Chitosan - TPP Nanoparticles Intended for Gene Delivery," Colloids and Surfaces B: Biointerfaces, Vol. 44, No. 2-3, 2005, pp. 65-73.

[6] P. He, S. S. Davis and L. Illum, "In vitro Evaluation of the Mucoadhesive Properties of Chitosan Microspheres," International Journal of Pharmaceutics, Vol. 166, No. 1, 1998, pp. 75-88. doi:10.1016/S0378-5173(98)00027-1

[7] A. B. Schnurch, C. Humenberger, C. Valenta, "Basic Studies on Bioadhesive Delivery Systems for Peptide and Protein Drugs," International Journal of Pharmaceutics, Vol. 165, No. 2, 1998, pp. 217-225. 


\section{doi:10.1016/S0378-5173(98)00017-9}

[8] M. Yalpani, F. Johnson, L. E. Robinson, "Chitin, Chitosan: Sources, Chemistry, Biochemistry, Physical Properties and Applications," Elsevier, Amsterdam, 1992.

[9] H. Tseng, K. Furhata and M. Sakamoto, "Bromination of Regenerated Chitin with N-Bromosuccinimide and Triphenylphosphine under Homogeneous Conditions in Lithium Bromide-N,N-Dimethylacetamide," Carbohydrate Research, Vol. 270, No. 2, 1995, pp. 149-161. doi:10.1016/0008-6215(95)00004-D

[10] W. M. Hou, S. Miyazaki, M. Takada and T. Komai, "Sustained Release of Indomethacin from Chitosan Granules," Chemical \& Pharmaceutical Bulletin, Vol. 33, No. 9, 1985, pp. 3986-3992.

[11] S. Miyazaki, K. Ishii and T. Nadai, "The Use of Chitin and Chitosan as Drug Carriers," Chemical \& Pharmaceutical Bulletin, Vol. 29, No. 10, 1981, pp. 3067-3069.

[12] L. Illum, "Chitosan and Its Use as Pharmaceutical Excipient," Pharmaceutical Research, Vol. 15, No. 9, 1998, pp. 1326-1331. doi:10.1023/A:1011929016601

[13] T. Chandy and C. P. Sharma, "Chitosan - As a Biomaterial," Biomaterials, Artificial Cells and Artificial Organs, Vol. 18, No. 1, 1990, pp. 1-24.

[14] T. Chandy and C. P. Sharma, "Biodegradable Chitosan Matrix for the Controlled Release of Steroids," Biomaterials, Artificial Cells and Immobilization Biotechnology, Vol. 19, No. 4, 1991, pp. 745-760.

[15] N. B. Graham, "Controlled Drug Delivery Systems," Chemical Industries, Vol. 15, 1990, pp. 482-486.

[16] T. Chandy and C. P. Sharma, "Chitosan Beads and Granules for Oral Sustained Delivery of Nifedipine: In vitro studies," Biomaterials, Vol. 13, No. 13, 1992, pp. 949-952. doi:10.1016/0142-9612(92)90119-9

[17] K. C. Gupta and M. N. V. Ravi Kumar, "Drug Release Behavior of Beads and Microgranules of Chitosan," Biomaterials, Vol. 21, No. 11, 2000, pp. 1115-1119. doi:10.1016/S0142-9612(99)00263-X

[18] F. L. Mi, H. W. Sung and S. S. Shyu, "Drug Release from Chitosan - Alginate Complex Beads Reinforced by a Naturally Occurring Crosslinking Agent," Carbohydrate Polymers, Vol. 48, No. 1, 2002, pp. 61-72. doi:10.1016/S0144-8617(01)00212-0

[19] M. V. D. Lubben, F. A. C. Van Opdorp, M. R. Hengeveld, J. J. M. Onderwater, H. K. Koerten, J. C. Verhoef, G. Borchard and H. E. Junginger, "Transport of Chitosan Microparticles for Mucosal Vaccine Delivery in a Human Intestinal M-Cell Model," Journal of Drug Target, Vol. 10, No. 6, 2002, pp. 449-456. doi:10.1080/1061186021000038319

[20] M. Amidi, S. G. Romeijn, J. C. Verhoef, H. E. Junginger, L. Bungener, A. Huckriede, D. J. A. Crommelin and W. Jiskoot, "N-Trimethyl Chitosan (TMC) Nanoparticles Loaded with Influenza Subunit Antigen for Intranasl VacCination: Biological Properties and Immunogenicity in a Mouse Model," Vaccine, Vol. 25, No. 1, 2007, pp. 144-153. doi:10.1016/i.vaccine.2006.06.086

[21] S. Danielsen, K. M. Varum and B. T. Stokke, "Structural Analysis of Chitosan Medicated DNA Condensation by
AFM: Influence of Chitosan Molecular Parameters," Biomacromolecules, Vol. 5, No. 3, 2004, pp. 928-936. doi: $10.1021 / \mathrm{bm} 034502 \mathrm{r}$

[22] S. Mansouri, P. Lavigne, K. Corsi, M. Benderdour, E. Beaumont, et al. "Chitosan-DNA Nanoparticles as Non Viral Vectors in Gene Therapy: Strategies to Improve Transfection Efficacy," European Journal of Pharmaceutics and Biopharmaceutics, Vol. 57, No. 1, 2004, pp. 1-8. doi:10.1016/S0939-6411(03)00155-3

[23] K. Wong, G. Sun, X. Zhang, H. Dai, Y. Liu, C. He, et al. "PEI-g-Chitosan, a Novel Gene Delivery System with Transfection Efficiency Comparable to Polyethyleneimine in Vitro and after Liver Administration in Vivo," Bioconjugate Chemistry, Vol. 17, No. 1, 2006, pp. 152-158. doi:10.1021/bc0501597

[24] N. Iwasaki, S. T. Yamane, T. Majima, Y. Kasahara, A. Minami, K. Harada, et al. "Feasibility of Polysaccharide Hybrid Materials for Scaffolds in Cartilage Tissue Engineering: Evaluation of Chondrocyte Adhesion to Polyion Complex Fibres Prepared from Alginate and Chitosan," Biomacromolecules, Vol. 5, No. 3, 2004, pp. 828-833. doi: $10.1021 / \mathrm{bm} 0400067$

[25] A. P. Zhu, Z. Ming and S. Jian, "Blood Compatibility of Chitosan/Heparin Complex Surface Modified ePTFE Vascular Graft," Applied Surface Science, Vol. 241, No. 3-4, 2005, pp. 485-492. doi:10.1016/j.apsusc.2004.07.055

[26] D. A. Zaharoff, C. J. Rogers, K. W. Hance, J. Schlom and J. W. Greiner, "Chitosan Solution Enhances Both $\mathrm{Hu}-$ moral and Cell-Medicated Immune Responses to Subcutaneous Vaccination," Vaccine, Vol. 25, No. 11, 2007, pp. 2085-2094. doi:10.1016/j.vaccine.2006.11.034

[27] J. Berger, M. Reist, J. M. Mayer, O. Felt and R. Gurny, "Structure and Interactions in Chitosan Hydrogels Formed by Complexation or Aggregations for Biomedical Applications," European Journal of Pharmaceutics and Biopharmaceutics, Vol. 57, No. 1, 2004, pp. 35-52. doi:10.1016/S0939-6411(03)00160-7

[28] J. Berger, M. Reist, J. M. Mayer, O. Felt, N. A. Peppas and R. Gurny, "Structure and Interactions in Covalently and Ionically Crosslinked Chitosan Hydrogels for Biomedical Applications," European Journal of Pharmaceutics and Biopharmaceutics, Vol. 57, No. 1, 2004, pp. 19-34. doi:10.1016/S0939-6411(03)00161-9

[29] M. N. V. Ravi kumar, "A Review of Chitin and Chitosan Applications," Reactive and Functional Polymers, Vol. 46, No. 1, 2000, pp. 1-27.

[30] J. Kost and R. Langer, "Hydrogels in Medicines and Pharmacy” In: N. A. Peppas, Ed., Hydrogels in Medicines and Pharmacy, CRC Press, Boca Raton, 1987, p. 95.

[31] K. D. Yao, T. Peng, H. B. Feng, Y. Y. He, "Swelling Kinetics and Release Characteristics of Crosslinked Chitosan-Polyether Polymer Network (semi IPN) Hydrogels," Journal of Polymer Science Part A: Polymer Chemistry, Vol. 32, No. 7, 1994, pp. 1213-1223. doi:10.1002/pola.1994.080320702

[32] I. F. Amaral, M. Lamghari, S. R. Sousa, P. Sampaio and M. A. Barbosa, "Rat Bone Marrow Stromal Cell Osteogenic Differentiation and Fibronecetin Adsorption on Chitosan Membranes: The Effect of Degree of Acetyla- 
tion," Journal of Biomedical Materials Research, Vol. 75A, No. 2, 2005, pp. 387-397. doi:10.1002/jbm.a.30436

[33] I. F. Amaral, P. Sampaio and M. A. Barbosa, "Three-Dimensional Culture of Human Osteoblastic Cells in Chitosan Sponges: The Effect of the Degree of Acetylation," Journal of Biomedical Materials Research, Vol. 76A, No. 2, 2005, pp. 335-346. doi:10.1002/jbm.a.30522

[34] T. Jung, W. Kamm, A. Breitenbach, E. Kaiserling, J. X. Xiao and T. Kissel, "Biodegradable Nanoparticles for Oral Delivery of Peptides: Is There a Role for Polymers to affect Mucosal Uptake?" European Journal of Pharmaceutics and Biopharmaceutics, Vol. 50, No. 1, 2000, pp. 147-160. doi:10.1016/S0939-6411(00)00084-9

[35] M. K. S. Batista, L. F. Pinto, C. A. L. Gomes and P. Gomes, "Novel Highly-Soluble Peptide - Chitosan Polymer: Chemical Synthesis and Spectral Characterization," Carbohydrate polymers, Vol. 64, No. 2, 2006, pp. 299-305. doi:10.1016/j.carbpol.2005.11.040

[36] P. Gomes, C. A. R. Gomes, M. K. S. Batista, L. F. Pinto and P. A. P. Silva, "Synthesis, Structural Characterization and Properties N-(Propanoyl-amino acid )-Chitosan," Carbohydrate Polymers, Vol. 71, No. 1, 2008, pp. 54-65. doi:10.1016/j.carbpol.2007.05.015

[37] M. Rani, A. Agarwal, T. Maharana and Y. S. Negi, "A Comparative Study for Interpenetrating Polymeric Network (IPN) of Chitosan-amino Acid Beads for Controlled Drug Release," African Journal of Pharmacy and Pharmacology, Vol. 4, No. 2, 2010, pp. 35-54.

[38] S. A. Agnihotri, N. N. mallikarjuna and T. M. Aminabhavi, "Review on Recent Advances on Chitosan Based Micro and Nanoparticles in Drug Delivery," Journal of Controlled Release, Vol. 100, No. 1, 2004, pp. 5-28. doi:10.1016/j.jconrel.2004.08.010

[39] E. Laszlo, L. Vlase and S. E. Leucuta, "Kinetic Modeling of Drug Release from Experimental Pharmaceutical Gels Containing Clotrimazole," Farmacia, Vol. 54, No. 3, 2006, pp. 25-32.

[40] T. Higuchi, "Mechanism of Sustained Action Medication," Journal of Pharmaceutical Sciences, Vol. 52, No. 12, 1963, pp. 1145-1149.

[41] K. Kumari and P. P. Kundu, "Studies on in Vitro Release of CPM from Semi-Interpenetrating Polymer Network (IPN) Composed of Chitosan and Glutamic Acid," Bulletin of Materials Science, Vol. 31, No. 2, 2008, pp. 159-167. doi:10.1007/s12034-008-0028-y

[42] K. Kumari and P. P. Kundu, "Semiinterpenetrating Polymer Networks (IPN) of Chitosan and L-Alanine for Monitoring the Release of Chlorpheniramine Maleate," Journal of Applied Polymer Science, Vol. 103, No. 6, 2007, pp. 3751-3757. doi:10.1002/app.25432

[43] T. Yoshioka, R. Hirano, T. Shioya and M. Kako, "Encapsulation of Mammalian Cell with Chitosan-CMC capsule," Biotechnology and Bioengineering, Vol. 35, No. 1, 1990, pp. 66-72. doi:10.1002/bit.260350110

[44] T. Peng, K. D. Yao, C. Yuan and M. F. Goosan, "Struc- tural Changes of PH Sensitive Chitosan/Polyether Hydrogels in Different PH Solution," Journal of Polymer Science.Part A: Polymer chemistry, Vol. 32, No. 3, 1994, pp. 591-596. doi:10.1002/pola.1994.080320322

[45] T. Sannan, K. Kurita, K. Ogura and Y. Iwakura, "Studies on Chitin: 7. IR Spectroscopic Determination of Degree of Deacetylation," Polymer, Vol. 19, 1978, pp. 458- 459. doi:10.1016/0032-3861(78)90256-2

[46] L. J. Bellamy, "The Infrared Spectra of Complex Molecles," Chapman \& Hall, London, New York, 1980.

[47] J. W. Lee, S. Y. Kim, S. G. Kim, Y. M. Lee, K. H. Lee and S. J. Kim, "Synthesis and Characteristics of Interpenetrating Polymer Network Hydrogel Composed of Chitosan and Poly Acrylic Acid," Journal of Applied Polymer Science, Vol. 73, No. 1, 1999, pp. 113-120. doi:10.1002/(SICI)1097-4628(19990705)73:1<113::AIDAPP13>3.0.CO;2-D

[48] A. P. Rokhade, N. B. Shelke, S. A. Patil and T. M. Aminabhavi, "Novel Interpenetrating Polymer Network Microspheres of Chitosan and Methylcellulose for Controlled Release of Theophylline," Carbohydrate polymer, Vol. 69, No. 4, 2007, pp. 678-687. doi:10.1016/j.carbpol.2007.02.008

[49] K. S. V. K. Rao, B. V. K. Naidu, M. C. S. Subha, M. Sairam and T. M. "Aminabhavi, Novel Chitosan-Based $\mathrm{Ph}$-Sensitive Interpenetrating Network Microgels for the Controlled Release of Cefadroxil," Carbohydrate Polymers, Vol. 66, No. 3, 2006, pp. 333-344. doi:10.1016/i.carbpol.2006.03.025

[50] S. A. Agnihotri and T. M. Aminabhavi, "Novel Interpenetrating Network Chitosan-Poly (Ethylene Oxide-g-Acryl Amide) Hydrogel Microspheres for the Controlled Release of Capecitabine," International Journal of Pharmaceutics, Vol. 324, No. 2, 2006, pp. 103-115. doi:10.1016/j.ijpharm.2006.05.061

[51] V. H. Kulkarni, P. V. Kulkarni and J. Keshavayya, "Glutaraldehyde-crosslinked Chitosan Beads for Controlled Release of Diclofenac Sodium," Journal of Applied Polymer Science, Vol. 103, No. 1, 2007, pp. 211-217. doi:10.1002/app. 25161

[52] S. R. Jameela, T. V. Kumary, A. V. Lal and A. Jayakrishna, "Progesterone Loaded Chitosan Microspheres: A Long Acting Biodegradable Controlled Delivery System," Journal of Control release, Vol. 52, No. 1-2, 1998, pp. 17-24.

[53] I. Orienti, K. Aiedeh, E. Gianasi, V. Bertasi and V. Zecchi, "Indomethacin Loaded Chitosan Microspheres Correlation between the Erosion Process and Release Kinetics," Journal of Microencapsulation, Vol. 13, No. 4, 1996, pp. 463-472. doi:10.3109/02652049609026031

[54] A. Ganza-Gonzalez, S. Anguiano-igea, F. J. Otero-Espinar and J. Blanco Mendez, "Chitosan and Chondroitin Microspheres for Oral Administration Controlled Release of Metoclopramide," European journal of pharmaceutics and Biopharmaceutics, Vol. 48, No. 2, 1999, pp. 149-155. doi:10.1016/S0939-6411(99)00040-5 